\title{
Time spent playing outdoors after school and its relationship with independent mobility: a cross-sectional survey of children aged 10 12 years in Sydney, Australia Li Ming Wen*1, James Kite ${ }^{1}$, Dafna Merom ${ }^{2}$ and Chris Rissel ${ }^{1}$
}

\author{
Address: ${ }^{1}$ Health Promotion Service, Sydney South West Area Health Service, Syndey, Australia and ${ }^{2}$ School of Public Health, University of Sydney, \\ Sydney, Australia \\ Email: Li Ming Wen* - Imwen@email.cs.nsw.gov.au; James Kite - james.kite@sswahs.nsw.gov.au; Dafna Merom - dafnam@health.usyd.edu.au; \\ Chris Rissel - criss@email.cs.nsw.gov.au \\ * Corresponding author
}

Published: 16 March 2009

International Journal of Behavioral Nutrition and Physical Activity 2009, 6:15 doi:10.1186/1479-5868-6-15

This article is available from: http://www.ijbnpa.org/content/6/I//5

(C) 2009 Wen et al; licensee BioMed Central Ltd.

This is an Open Access article distributed under the terms of the Creative Commons Attribution License (http://creativecommons.org/licenses/by/2.0), which permits unrestricted use, distribution, and reproduction in any medium, provided the original work is properly cited.
Received: 13 November 2008

Accepted: 16 March 2009

\begin{abstract}
Background: Time spent outdoors is positively associated with physical activity and has been suggested as a proxy for physical activity of children. The role of children's independence in physical activity and time spent outdoors is less understood. This study aimed to assess how much time children spent playing outdoors after school, and to explore the relationship between outdoor play and independence among children aged $10-12$ years.
\end{abstract}

Method: Children recorded how much time they spent playing outdoors or watching TV/videos or playing computer games after school using a five-day diary, and also reported whether they were allowed to walk on their own in their neighbourhood as an indicator of their independent mobility. Parents were surveyed on family demographics and perception of neighbourhood safety. The surveys were conducted in late 2006 as part of the Central Sydney Walk to School program which involved 1975 children and their parents from 24 primary schools. Factors associated with time spent playing outdoors were determined by logistic regression modelling.

Results: Thirty-seven per cent of children spent less than half an hour a day playing outdoors after school, and $43 \%$ spent more than 2 hours a day watching TV, videos or playing computer games. Forty-eight per cent of children were allowed to walk on their own near where they lived. Children's independent mobility was significantly associated with outdoor play after adjusting for other confounders. Compared with those who were never allowed to walk on their own near where they lived, students who were allowed to walk on their own were significantly more likely to spend more than half an hour a day playing outdoors after school with an adjusted odds ratio of 2.6, 95\% Cl I.84-3.58, P $<0.001$.

Conclusion: The findings that a significant proportion of children spend less than half an hour a day playing outdoors after school and have excessive screen time have important implications for physical activity promotion and obesity prevention. The study also suggests that children's independent mobility should be considered in research and evaluation into children's play and physical activity. Environments that promote greater independent mobility in children may increase their physical activity levels and hence reduce their risk of overweight/obesity. 


\section{Background}

Promoting physical activity is an important strategy in tackling the epidemic of childhood overweight and obesity. Children participating in leisure-time physical activity have been found to be significantly less likely to be overweight than children who reported no leisure-time physical activity $[1,2]$. Australian physical activity guidelines recommend children spend a minimum of 60 minutes per day in moderate to vigorous physical activity, and be part of play, games, sports, transportation, recreation, physical education class or planned exercise [3]. Conversely, they should spend no more than 120 minutes per day engaged in small screen entertainment [3].

However, assessing children's level of physical activity can be challenging and costly. To our knowledge, to date there are no validated survey questionnaires that have been developed for assessing level of physical activity for primary school children. Direct measures such as observation and accelerometers can be used but are often not feasible in large epidemiologic studies.

Time spent outdoors is positively associated with physical activity levels of children [4-6], and has been suggested as a proxy for physical activity [7]. A recent study conducted by Cleland et al concluded that encouraging 10- to 12 year-old children to spend more time outdoors may be an effective strategy for increasing physical activity and preventing overweight and obesity in children [8].

Children's independence can be defined as the ability to take responsibility for their own behaviour without unnecessary reliance on their parents or carers. Every child has the potential for some degree of independence in their daily lives. Developing independence is an important goal for all children and is an ongoing process that continues throughout childhood, adolescence, and even into adulthood [9]. However, the role of children's independence in physical activity and time spent outdoors is less understood.

The aims of this study were to assess how much time students spent playing outdoors after school, and to explore the relationship between outdoor play and independent mobility among children aged $10-12$ years $\left(5^{\text {th }}\right.$ and $6^{\text {th }}$ year students).

\section{Methods}

\section{Study design}

A cross-sectional survey was conducted in October, 2006 as part of the evaluation of the Central Sydney Walk to School Research Program, which has been reported in detail elsewhere [10]. The research program was approved by the ethics committees of Sydney South West Area Health Service, and the NSW Department of Education and Training.

\section{Study participants}

Twenty-four schools located in inner west Sydney volunteered to be part of the study. Participating schools varied in size, socio-economic status of students and their families, and cultural mix. All $5^{\text {th }}$ and $6^{\text {th }}$ year students, aged $10-12$ years, in the participating schools $(\mathrm{n}=2230)$ were recruited for the survey, and their parents were also invited to take part in the survey with a letter giving detailed information about the study.

\section{Data collection}

The student survey was conducted in class and supervised by teachers over five consecutive school days, using a diary format. Class teachers distributed copies of the parent survey to their students to take home. Parents completed the surveys at home, if they chose to participate, and returned their completed survey to the class teacher. The student and parent surveys were matched through a previously used anonymous record linkage technique [11] based on the first letter of surname, class and year, and birth date of student.

\section{Measures}

Time spent playing outdoors, time spent on watching TV/ videos or playing computer games (also known as "screen time") and the independent mobility were collected from students' surveys. Family and demographic information was collected from the parents.

\section{$\hat{a}$ Time spent playing outdoors and screen time}

Student surveys contained questions that asked students to recall how much time they spent playing outdoors after school yesterday. Students answered the question by selecting one time slot out of six incremental options ranging from none to more than three hours with intervals of half an hour. The data were then summed and averaged over five days. An average time per day spent playing outdoors after school and an average screen time were calculated. Time spent playing outdoors for less than half an hour a day was considered "low". This cut-point was used because it represents a very low amount of physical activity and as such, this group was at greatest risk of developing health-related problems. Similarly, daily screen time (i.e. watching TV/videos and playing computer games) was also calculated by summing the responses for these activities and averaged over five days.

\section{a Independent Mobility}

Independent mobility was assessed by a single question, "are you allowed to walk on your own, near where you live?" Children were able to select one of three options, "mostly", "sometimes" and "never".

\section{â Family and demographic information and neighbourhood safety} The information was collected in the parent survey, which included their relation to the child, age, education level, 
employment status, language spoken at home, and the number of children at home. Parents were also asked if they agreed or disagreed with the statement, "I live in a safe neighbourhood" by a scale from " 1 " to ' 5 " where " 1 " represents "strongly agreed" and "5" represents "strongly disagreed".

\section{Analysis}

Statistical analyses were carried out using the computer package SPSS Complex Samples Statistics (Version 14.0) [12], which incorporates the sampling design into survey analysis. It is widely used to allow for cluster sampling and unequal probability of selection.

Relationships between study and outcome variables were examined using Pearson chi-square tests and MantelHaesnszel chi-square tests for trend in proportions. Variables that were found to be associated with time spent playing outdoors on bi-variate analyses were entered into a logistic regression model.

In the logistic regression analysis all variables were entered in one step and removed from the model according to their statistical significance on entry, and whether they met the removal criterion $(\mathrm{P}=0.10)$. Adjusted odds ratios (AORs) with 95\% confidence intervals were calculated as a measure of association. A similar process was applied to examine whether correlates were different for boys or girls.

\section{Results}

Response rate and study respondents

A total of 1974 students completed a five-day diary survey giving a response rate of $89 \%$, but only 1362 parents completed the parent survey giving a response rate of $61 \%$. In this analysis, children without their parent survey data were excluded ( $n=612$ ). There were no statistically significant differences in relation to time spent playing outdoors, screen time and the independent mobility between those who remained in the analysis and those excluded.

Table 1 shows the characteristics of the students and parents remaining in the analysis $(\mathrm{n}=1362)$. Of these students, $47 \%$ were boys. The majority of survey respondents were mothers $(80 \%)$. Forty per cent of parents were employed full-time, $42 \%$ had a tertiary degree, and $42 \%$ spoke a language other than English at home. About half of the families had two children at home.

\section{Time spent playing outdoors, screen time and independent mobility}

Table 2 shows time spent playing outside, screen time and independent mobility as reported by children, as well as neighbourhood safety as reported by parents. Overall,
Table I: Characteristics of the study participants

\begin{tabular}{|c|c|}
\hline Characteristics & $\begin{array}{r}N=1362 \\
n *(\%)\end{array}$ \\
\hline \multicolumn{2}{|l|}{ Student Gender } \\
\hline Girl & $710(53 \%)$ \\
\hline Boy & $638(47 \%)$ \\
\hline \multicolumn{2}{|l|}{ Student School Year } \\
\hline Year 5 & $693(51 \%)$ \\
\hline Year 6 & $656(49 \%)$ \\
\hline \multicolumn{2}{|l|}{ Respondent } \\
\hline Mother & $1061(80 \%)$ \\
\hline Father & $241(18 \%)$ \\
\hline Other & $28(2 \%)$ \\
\hline \multicolumn{2}{|l|}{ Parent Age } \\
\hline Less than 30 yrs & $33(3 \%)$ \\
\hline $30-39$ yrs & $406(30 \%)$ \\
\hline $40-49$ yrs & $777(58 \%)$ \\
\hline $50+$ & $128(9 \%)$ \\
\hline \multicolumn{2}{|l|}{ Language spoken at home } \\
\hline English & 792 (58\%) \\
\hline Other & $570(42 \%)$ \\
\hline \multicolumn{2}{|l|}{ Parent Education } \\
\hline Primary and some high school & $128(12 \%)$ \\
\hline Completed high school & $245(22 \%)$ \\
\hline Technical certificate or diploma & $277(25 \%)$ \\
\hline University/Other tertiary degree & $473(42 \%)$ \\
\hline \multicolumn{2}{|l|}{ Parent Employment Status } \\
\hline Employed full-time & $535(40 \%)$ \\
\hline Employed part-time & $378(28 \%)$ \\
\hline Full/part-time student & $38(3 \%)$ \\
\hline Home duties & $264(20 \%)$ \\
\hline Unemployed & $59(4 \%)$ \\
\hline Retired/other & $17(5 \%)$ \\
\hline \multicolumn{2}{|l|}{ Number of Children at home } \\
\hline 1 & $336(25 \%)$ \\
\hline 2 & $643(48 \%)$ \\
\hline 3 & $277(21 \%)$ \\
\hline $4+$ & $77(6 \%)$ \\
\hline \multicolumn{2}{|l|}{ Parent Living with Partner } \\
\hline Yes & 955 (84\%) \\
\hline No & $185(16 \%)$ \\
\hline \multicolumn{2}{|l|}{ Time Living in the Area } \\
\hline Less than one year & $136(10 \%)$ \\
\hline From I-2 yrs & $155(12 \%)$ \\
\hline From $2-5$ yrs & 245 (18\%) \\
\hline From $5-10$ yrs & $327(24 \%)$ \\
\hline More than 10 yrs & $483(36 \%)$ \\
\hline
\end{tabular}

*May not add up to 1362 due to missing data 
$37 \%$ of children spent up to half an hour a day after school playing outdoors. More boys than girls spent two hours or more a day playing outdoors (20\% vs. $12 \%$, p < 0.001). Boys were also more likely to spend more than two hours a day on screens (i.e. TV and computer) than girls $(49 \%$ vs. $36 \%, \mathrm{p}<0.001)$. Almost one fifth of children $(18 \%)$ were never allowed to walk on their own near where they lived. Boys were more likely to have greater independent mobility than girls $(53 \%$ vs. $42 \%$, p < $0.001)$.

More than half of the parents or caregivers (59\%) either agreed or strongly agreed with the statement, "I live in a safe neighbourhood". There was no significant difference in relation to the perception of neighbourhood safety between boys' and girls' parents and carers. About one third $(30 \%)$ of parents and carers neither agreed nor disagreed with this statement.

\section{Factors associated with time spent playing outdoors}

On bi-variate analysis, factors that were associated with time spent playing outdoors after school included children's independent mobility, language spoken at home, employment status of parents and caregivers, length of time living in the area, neighbourhood safety and number of children $(\mathrm{p}<0.10)$ (Table 3). However, factors including child's gender, school year, parent's age, educational level of parent and whether the parent lived with a partner were not found to be associated with time spent outdoors.

The results of the multivariate analysis are shown in Table 4. The association between time spent playing outdoors after school and children's independent mobility retained its significance after adjusting for other confounders. Compared with children who were never allowed to walk on their own near where they lived, children who had been allowed to walk on their own sometimes or mostly were significantly more likely to spend more than half an hour a day outdoors after school with AORs of 1.74 (95\% CI 1.24-2.45; $\mathrm{P}<0.001)$ and 2.56 (95\% CI 1.84-3.58; P $<0.001)$ respectively. Children who spoke English at home were also more likely to spend more time playing outdoors compared to non-English speaking children with an AOR of 1.99 (95\% CI 1.54-2.56; P < 0.001). The parent being employed and neighbourhood safety were also significantly associated with children's time spent outdoors. Stratification by gender did not show any differences between boys and girls in relation to the variables that were associated with time spent playing outdoors.

Table 2: Time spent playing outside, screen time, independent mobility and neighbourhood safety as reported by students and their parents

\begin{tabular}{|c|c|c|c|c|}
\hline & Girl n (\%) & Boy n (\%) & Total n (\%) & $\begin{array}{r}\text { Chi-Square } \\
\text { P value }\end{array}$ \\
\hline \multicolumn{5}{|l|}{ Outdoor Play Time } \\
\hline $\mathrm{T} \leq \mathrm{I} / 2$ hour & $27 \mathrm{I}(38 \%)$ & $231(36 \%)$ & $502(37 \%)$ & $\begin{array}{r}7.34 \\
P<0.001\end{array}$ \\
\hline $\mathrm{I} / 2$ hour $<\mathrm{T} \leq \mathrm{I}$ hour & $165(23 \%)$ & $123(19 \%)$ & $288(22 \%)$ & \\
\hline I hour $<\mathrm{T} \leq 2$ hours & $186(26 \%)$ & $156(25 \%)$ & $342(26 \%)$ & \\
\hline$T>2$ hours & $83(12 \%)$ & $126(20 \%)$ & $209(16 \%)$ & \\
\hline \multicolumn{5}{|l|}{ Screen Time } \\
\hline $\mathrm{T} \leq \mathrm{I} / 2$ hour & 105 (15\%) & 77 (12\%) & $182(14 \%)$ & $\begin{array}{r}15.41 \\
P<0.001\end{array}$ \\
\hline $\mathrm{I} / 2$ hour $<\mathrm{T} \leq \mathrm{I}$ hour & 105 (15\%) & 95 (15\%) & $200(15 \%)$ & \\
\hline I hour $<\mathrm{T} \leq 2$ hours & $236(34 \%)$ & $152(24 \%)$ & 388 (29\%) & \\
\hline 2 hours $<T \leq 3$ hours & 135 (19\%) & $|4|(22 \%)$ & $276(21 \%)$ & \\
\hline $\mathrm{T}>3$ hours & $120(17 \%)$ & I7I (27\%) & 291 (22\%) & \\
\hline \multicolumn{5}{|l|}{ Independence } \\
\hline Mostly & $283(42 \%)$ & $316(53 \%)$ & $599(47 \%)$ & $\begin{array}{r}17.15 \\
P<0.001\end{array}$ \\
\hline Sometimes & $244(37 \%)$ & 202 (34\%) & 446 (35\%) & \\
\hline Never & $142(21 \%)$ & $84(14 \%)$ & $226(18 \%)$ & \\
\hline \multicolumn{5}{|c|}{ Neighbourhood Safety reported by parents } \\
\hline Safe & $390(57 \%)$ & $375(61 \%)$ & $765(59 \%)$ & $\begin{array}{r}2.39 \\
P=0.068\end{array}$ \\
\hline Not sure or not safe & $296(43 \%)$ & $239(39 \%)$ & $535(41 \%)$ & \\
\hline
\end{tabular}

"Independence" is assessed by a question "are you allowed to walk on your own, near where you live" as reported by students.

"Neighbourhood Safety" is assessed by a scale from I to 5 of agreement with the statement "I live in a safe neighbourhood" as reported by parents. 
Table 3: Factors associated with time spent playing outside on bi-variate analysis

\begin{tabular}{|c|c|c|c|}
\hline & \multicolumn{2}{|c|}{ Time spent playing outside } & \multirow{2}{*}{$\begin{array}{l}\text { Chi-Squar } \\
\mathbf{P} \text { value }\end{array}$} \\
\hline & $\begin{array}{l}>0.5 \text { hour } \\
N(\%)\end{array}$ & $\begin{array}{c}<0.5 \text { hour } \\
N \text { (\%) }\end{array}$ & \\
\hline \multicolumn{4}{|l|}{ Independence } \\
\hline Mostly & $427(53 \%)$ & $179(37 \%)$ & $\begin{array}{r}44.58 \\
P<0.001\end{array}$ \\
\hline Sometimes & $273(34 \%)$ & $177(37 \%)$ & \\
\hline Never & $103(13 \%)$ & $124(26 \%)$ & \\
\hline \multicolumn{4}{|l|}{ Neighbourhood Safety } \\
\hline Safe & $494(61 \%)$ & $269(56 \%)$ & $\mathrm{P}=\begin{array}{l}3.42 \\
0.06\end{array}$ \\
\hline Not sure or not safe & $320(39 \%)$ & $216(45 \%)$ & \\
\hline \multicolumn{4}{|l|}{ Child's Gender } \\
\hline Girl & $434(52 \%)$ & $271(54 \%)$ & $P=\begin{array}{l}0.64 \\
P=0.43\end{array}$ \\
\hline Boy & $405(48 \%)$ & $231(46 \%)$ & \\
\hline \multicolumn{4}{|l|}{ School Year } \\
\hline Year 5 & $423(50 \%)$ & $265(53 \%)$ & $\begin{array}{r}0.646 \\
P=0.42\end{array}$ \\
\hline Year 6 & $416(50 \%)$ & $238(47 \%)$ & \\
\hline \multicolumn{4}{|l|}{ Language spoken at home } \\
\hline English & $550(65 \%)$ & $239(47 \%)$ & $\begin{array}{r}40.457 \\
P<0.001\end{array}$ \\
\hline Other & $298(35 \%)$ & $267(53 \%)$ & \\
\hline \multicolumn{4}{|l|}{ Career } \\
\hline Mother & $668(80 \%)$ & $393(79 \%)$ & $\begin{array}{r}0.781 \\
P=0.38\end{array}$ \\
\hline Father & $153(18 \%)$ & $88(18 \%)$ & \\
\hline Other & $13(2 \%)$ & $15(35)$ & \\
\hline \multicolumn{4}{|l|}{ Employment Status } \\
\hline Full-time \& part time & $597(71 \%)$ & $311(62 \%)$ & $\begin{array}{r}11.852 \\
P<0.001\end{array}$ \\
\hline Other & $239(29 \%)$ & $188(38 \%)$ & \\
\hline \multicolumn{4}{|l|}{ Parent Education } \\
\hline Primary and some high school & $108(11 \%)$ & $77(14 \%)$ & $P=\begin{array}{l}1.545 \\
0.214\end{array}$ \\
\hline Completed high school & $227(22 \%)$ & $108(20 \%)$ & \\
\hline Technical certificate or diploma & $243(24 \%)$ & $148(27 \%)$ & \\
\hline University/other tertiary degree & $436(43 \%)$ & $220(40 \%)$ & \\
\hline \multicolumn{4}{|l|}{ Living with Partner } \\
\hline Yes & $602(84 \%)$ & $348(83 \%)$ & $P=\begin{array}{l}0.35 \\
0.56\end{array}$ \\
\hline No & $113(16 \%)$ & $72(17 \%)$ & \\
\hline \multicolumn{4}{|l|}{ Time Living in Area } \\
\hline Less than one year & $88(11 \%)$ & $48(10 \%)$ & $\mathrm{P}=\begin{array}{r}4.14 \\
0.04\end{array}$ \\
\hline From I-2 yrs & $89(11 \%)$ & $65(13 \%)$ & \\
\hline From 2-5 yrs & $142(17 \%)$ & $102(20 \%)$ & \\
\hline From $5-10$ yrs & $190(235)$ & $135(27 \%)$ & \\
\hline More than 10 yrs & $331(39 \%)$ & $149(30 \%)$ & \\
\hline \multicolumn{4}{|l|}{ Number of Children } \\
\hline 1 & $200(24 \%)$ & $136(27 \%)$ & $P=\begin{array}{l}3.56 \\
0.06\end{array}$ \\
\hline 2 & $396(48 \%)$ & $243(49 \%)$ & \\
\hline 3 & $177(21 \%)$ & $97(19 \%)$ & \\
\hline $4+$ & $54(7 \%)$ & $23(5 \%)$ & \\
\hline
\end{tabular}




\section{Discussion}

In this cross-sectional study, we found that a significant proportion of children (37\%) spent less than half an hour a day playing outdoors after school and $43 \%$ of children spent more than two hours a day on screen time. These findings have important implications for health promotion in addressing outdoor play and reducing excessive screen time among children. Previous research suggests that outdoor time is positively and significantly associated with children's physical activity [4-6] and excessive screen time (more than 2 hours a day) is also found to be significantly associated with overweight and obesity $[1,13,14]$.

In addition, this study found that children's independent mobility was a significant factor associated with their time spent playing outdoors after adjusting for other confounders including parent's perception of neighbourhood safety. Children's independent mobility was initially examined in relation to their independent mobility. In the UK, $61 \%$ of primary school children were rarely or never allowed to go outside without an adult to walk to school or for leisure. These children were twice as likely to be driven to school than to walk, after adjusting for parents' perception of safety [15]. The frequency of walking to school was also found to be dependent on child's independent mobility; in New South Wales $58 \%$ of parents to children 5- to 12-years-old never allowed their child to walk alone in their neighbourhood, and these children were $42 \%$ less likely to frequently walk to school [16]. To our knowledge this is the first time such an association between children's independent mobility and their time spent playing outdoors has been tested in a quantitative study with a large sample size.

Several studies have touched on the issue about children's independence and physical activity but they have mostly explored it from the perspective of the parents. That is, these studies have considered why parents may restrict independence but have not thoroughly explored how a child's independent mobility influences his/her physical activity levels. For instance, some studies have explored the factors which influence parents' decisions regarding the selection of appropriate play areas and travel methods $[7,17-21]$ and these decisions would have a direct influ-

Table 4: Factors associated with time spent playing outside using logistic regression modelling

\begin{tabular}{|c|c|c|c|c|}
\hline \multirow[b]{2}{*}{ Study variables } & \multicolumn{4}{|c|}{ Spending more than 0.5 hour playing outside per day } \\
\hline & n (row \%) & Adjusted OR* & $95 \% \mathrm{Cl}$ & $\mathbf{p}$ \\
\hline \multicolumn{5}{|l|}{ Independence } \\
\hline Never & $103(45 \%)$ & I & & \\
\hline Sometimes & $273(61 \%)$ & 1.74 & $1.24-2.45$ & $P<0.001$ \\
\hline Mostly & $427(71 \%)$ & 2.56 & $1.84-3.58$ & $P<0.001$ \\
\hline \multicolumn{5}{|l|}{ Neighbourhood Safety } \\
\hline Not sure or not safe & $320(61 \%)$ & 1 & & \\
\hline Safe & $494(65 \%)$ & 1.28 & $1.0-1.64$ & $P=0.05$ \\
\hline \multicolumn{5}{|l|}{ Employment Status } \\
\hline Other duties & $239(56 \%)$ & I & & \\
\hline Employed & $597(66 \%)$ & 1.37 & $1.06-1.78$ & $P=0.02$ \\
\hline \multicolumn{5}{|l|}{ Child's Gender } \\
\hline Girl & $434(62 \%)$ & I & & \\
\hline Boy & 405 (67\%) & 1.02 & $0.80-1.30$ & $P=0.90$ \\
\hline \multicolumn{5}{|c|}{ Language spoken at home } \\
\hline Other & $298(53 \%)$ & I & & \\
\hline English & $550(70 \%)$ & 1.99 & $1.54-2.56$ & $P<0.001$ \\
\hline \multicolumn{5}{|l|}{ Time Living in the area } \\
\hline$\leq 2$ years & 177 (6I\%) & 1 & & \\
\hline$>2$ years & $663(63 \%)$ & 0.91 & $0.68-1.23$ & $P=0.55$ \\
\hline \multicolumn{5}{|c|}{ Number of Children at home } \\
\hline I & $200(60 \%)$ & I & & \\
\hline$>1$ & $627(63 \%)$ & 0.89 & $0.67-1.17$ & $P=0.40$ \\
\hline
\end{tabular}

* adjusted for all other variables in the table. 
ence on the independent mobility of children. Prezza et al argue that a parent's psychosocial characteristics (e.g. their fear of crime, perceived risk of traffic, sense of community etc.) influence the amount of independence that they allow their children [17].

Other studies have explored the decline in children's unsupervised play and the concurrent increase in organised games [22,23]. These studies suggest that the increased participation in organised games can be attributed to, at least partly, parents' views that this will keep children safer than unstructured play. As Evans points out "traditional playgrounds - the backyards and streets - are no longer play-friendly... [and] most parents are reluctant to allow children to play unless they are easily visible or an adult is present." [22] Organised games appeal to this reluctance as adults are able to direct play and ensure safety.

Similarly, the changing nature of play spaces has been found to make parents more wary of allowing children to play unsupervised [24-26]. In fact, both Hillman and Burdette and Whitaker argue that in trying to protect children we may actually be having detrimental effects on their social and emotional development $[25,26]$.

Caution needs to be taken when interpreting these findings as a result of the cross-sectional nature of this study and its reliance on measures that were self-reported by children and parents. The weakness of the study design and measurement errors (e.g. the possibility that the students may have over- or underestimated their time spent outdoors) may have weakened the conclusions generated from this study. The generalisation of our study results is also limited due to selection of the study population. However, this study reflects well the multicultural profile of the population in the study area and does provide some evidence linking children's independent mobility and time spent playing outdoors.

\section{Conclusion}

Our findings of this relationship have important implications for promoting physical activity among children. They suggest that environments that promote greater independent mobility in children aged 10-12 may increase their physical activity levels and hence reduce their risk of overweight and obesity. Health promotion programs, therefore, need to acknowledge the independent mobility of children and its relation with children's outdoor play. Program components need to address parents' concerns to allow their children to play and walk around their places. The findings also suggest that children's dependence should be considered in research and evaluation into children's play and physical activity. Equally, the reasons why children from a non-English speaking background were less likely to spend more time playing outdoors should be further explored.

\section{Competing interests}

The authors declare that they have no competing interests.

\section{Authors' contributions}

LMW conceived the idea of this study and undertook data analysis and interpretation and wrote the original draft. JK, DM and CR contributed to writing up this manuscript. All authors have read and approved the final manuscript.

\section{Acknowledgements}

The authors wish to thank parents for their participation in this study. We wish to thank teachers and principals from the participating schools for their time and support for this study. We thank members of the project team including Denise Fry, Helen Dirkis and Angela Balafas. We also thank Hui Lan for her assistance in data analysis. This study was a part of the Central Sydney Walk to School Research Program funded by NSW Health.

\section{References}

I. Trost S, Kerr L, Ward D, Pate R: Physical activity and determinants of physical activity in obese and non-obese children. Int J Obes 200I, 25:822-829.

2. Lioret S, Maire B, Volatier J, Charles M: Child overweight in France and its relationship with physical activity, sedentary behaviour and socioeconomic status. Eur J Clin Nutr 2007, 61:509-516.

3. Australian Government, Department of Health and Ageing: Australia's physical activity recommendations for 5-12 year olds. Canberra 2004

4. Klesges R, Eck L, Hanson C, Haddock C, Klesges L: Effects of obesity, social interactions, and physical environment on physical activity in preschoolers. Health Psychol 1990, 9:435-449.

5. Sallis J, Nader P, Broyles S, Berry C, Elder J, McKenzie TL, Nelson JA: Correlates of physical activity at home in Mexican-American and Anglo-American preschool children. Health Psychol 1993, 1 2:390-398.

6. Sallis J, Prochaska J, Taylor W: A review of correlates of physical activity of children and adolescents. Med Sci Sports Exerc 2000, 32:963-975.

7. Veitch J, Bagley S, Ball K, Salmon J: Where do children usually play? A qualitative study of parents' perceptions of influences on children's active free play. Health Place 2006, I 2:383-393.

8. Cleland V, Crawford D, Baur L, Hume C, Timperio A, Salmon J: A prospective examination of children's time spent outdoor, objectively measured physical activity and overweight. Int J Obes 2008, 32:1685-1693.

9. Encouraging your child's independence [http:// www.acd.org.au/information/content/ 13 encouraging your child's independence.pdf

10. Wen LM, Fry D, Merom D, Rissel C, Dirkis H, Balafas A: Increasing active travel to school: are we on the right track? A cluster randomised controlled trial from Sydney, Australia. Prev Med 2008, 47:6|2-618.

II. Winchester L, Dobbinson S, Rissel C, Bauman A: Anonymous record linkage using respondent-generated ID codes - a tool for health promotion research. Health Promot J Aust 1996, 6:52-54.

12. SPSS Inc: SPSS Complex Samples Statistics (Version 14.0) SPSS Inc, Chicago, IL USA.

13. Andersen R, Crespo C, Bartlett S, Cheskin L, Pratt M: Relationship of physical activity and television watching with body weight and level of fatness among children: results from the Third National Health and Nutrition Examination Survey. J Am Med Assoc 1998, 279:938-942.

14. Hernandez B, Gortmaker S, Colditz G, Peterson K, Laird N, ParaCabrera S: Association of obesity with physical activity, televi- 
sion programs and other forms of video viewing among children in Mexico City. Int J Obes 1999, 23:845-854.

15. DiGuiseppi C, Robert I, Leah L, Allen D: Determinants of car travel on daily journeys to school: cross sectional survey of primary school children. BMJ 1998, 316:|426-|428.

16. Merom D, Tudor-Locke C, Bauman A, Rissel C: Active commuting to school among NSW primary school children: implications for public health. Health Place 2006, 12:678-687.

17. Prezza M, Pilloni S, Morabito C, Sersante C, Alparone F, Giuliani M: The influence of psychosocial and environmental factors on children's independent mobility and relationship to peer frequentation. J Community Applied Social Psychol 200 I, I I:435-450.

18. Gielen A, DeFrancesco S, Bishai D, Mahoney P, Ho S, Guyer B: Child pedestrians: the role of parental beliefs and practices in promoting safe walking in urban neighbourhoods. J Urban Health 2004, 81 : :545-555.

19. Timperio A, Crawford D, Telford A, Salmon J: Perceptions about the local neighbourhood and walking and cycling among children. Prev Med 2004, 38:39-47.

20. Timperio A, Ball K, Salmon J, Roberts R, Giles-Corti B, Simmons D Baur L, Crawford D: Personal, family, social and environmental correlates of active commuting to school. Am J Prev Med 2006, 30:45-5I.

21. Boshoff K, Dollman J, Magarey A: An investigation into the protective factors for overweight among low socio-economic status children. Health Promot J Aust 2007, 18(2): I35- I 42.

22. Evans J: Where do the children play? Children Aust 2000, 25:35-40.

23. Carver A, Timperio A, Crawford D: Playing it safe: The influence of neighbourhood safety on children's physical activity - A review. Health Place 2008, 14:217-227.

24. Valentine G, McKendrick J: Children's outdoor play: exploring parental concerns about children's safety and the changing nature of childhood. Geoforum 1997, 28:219-235.

25. Burdette $H$, Whitaker $R$ : Resurrecting free play in young children; looking beyond fitness and fatness to attention, affiliation and affect. Arch Paediatr Adolesc Med 2005, 159:46-50.

26. Hillman M: Children's rights and Adults' wrongs. Children's Geographies 2006, 4:6I-67.
Publish with Biomed Central and every scientist can read your work free of charge

"BioMed Central will be the most significant development for disseminating the results of biomedical research in our lifetime. "

Sir Paul Nurse, Cancer Research UK

Your research papers will be:

- available free of charge to the entire biomedical community

- peer reviewed and published immediately upon acceptance

- cited in PubMed and archived on PubMed Central

- yours - you keep the copyright

Submit your manuscript here:

http://www.biomedcentral.com/info/publishing_adv.asp
BioMedcentral 